Recepción: 21/ 09 / 2018

Aceptación: 16 / 11 / 2018

Publicación: 03 / 12 / 2018

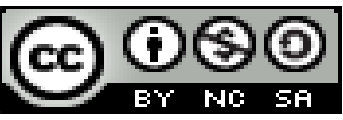

Ciencias económicas y empresariales

Artículo de investigación

\title{
La publicidad digital sobre las percepciones del elector durante la campaña electoral en la provincia de Tungurahua
}

Digital publicity about voter perceptions during the electoral campaign in Tungurahua province

Publicidade digital sobre as percepções dos eleitores durante a campanha eleitoral na província de Tungurahua

\author{
Pablo J. Guerrero-Zuñiga I \\ pablopichion@hotmail.com \\ Gabriela C. Sisa-Huiracocha II \\ gabosca17062005@ hotmail.com \\ Cesar A. Guerrero-Velástegui III \\ ca.guerrero@uta.edu.ec \\ Leonardo G. Ballesteros-López ${ }^{\text {IV }}$ \\ leonardogballesteros@uta.edu.ec
}

\section{Correspondencia: pablopichion@hotmail.com}

\footnotetext{
I Docente de la Universidad Técnica de Ambato, Ambato, Ecuador.

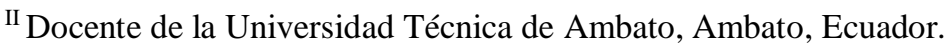

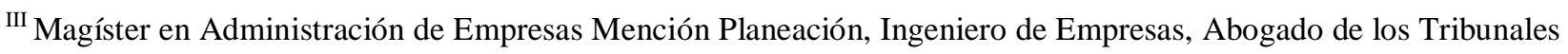
y Juzgados de la República del Ecuador, Docente de la Universidad Técnica de Ambato, Ambato, Ecuador.

IV Magíster en Gestión Estratégica Empresarial MBA, Ingeniero Comercial, Licenciado en Ciencias Administrativas Administrador en Mercadotecnia, Docente de la Universidad Técnica de Ambato, Ambato, Ecuador.
} 


\title{
Resumen
}

Las campañas electorales que realizan los diferentes partidos políticos, en el marco de los procesos democráticos de elecciones que se llevan a cabo en la actualidad ofrecen la oportunidad, de que se puedan utilizar tecnologías de información y comunicación y de esta manera dar a conocer y publicitar electoralmente a sus candidatos y sus ideologías políticas y de esa manera, los electores puedan elegir al mejor candidato, no sin antes tener muy en claro los pormenores de su elección; es aquí, que las tecnologías de información y comunicación tendrán un protagonismo importante en la transmisión de los mensajes publicitarios. La presente investigación tiene como objetivo estudiar la publicidad política basada en tecnologías de la información y comunicación, para lo cual se empleó un enfoque cuali-cuantitativo, sustentado por una investigación bibliográfica acerca de las variables objeto de estudio, además se realizó una investigación de campo donde la población a estudiar estuvo estructurado por los habitantes de la provincia de Tungurahua en edades comprendidas de 16 a 65 años a quienes se les aplico la encuesta como instrumento de recolección de información misma que estuvo estructurada con 20 preguntas obteniendo como principales hallazgos que el Facebook es la red social más utilizada seguida de Twitter e Instagram.

Palabras clave: marketing político; marketing electoral; publicidad política; tecnología de información y comunicación.

\begin{abstract}
The electoral campaigns carried out by the different political parties, within the framework of the democratic processes of elections that are carried out at present, offer the opportunity, that information and communication technologies can be used and in this way publicize and publicize electorally to their candidates and their political ideologies and in this way, the electors can choose the best candidate, but not before being very clear about the details of their election; It is here that information and communication technologies will have an important role in the transmission of advertising messages. The objective of this research is to study political advertising based on information and communication technologies, for which a qualitativequantitative approach was used, supported by a bibliographic research on the variables under study, and a field investigation was carried out. where the population to study was structured by
\end{abstract}


the inhabitants of the province of Tungurahua in ages ranging from 16 to 65 years to whom the survey was applied as an instrument of information collection that was structured with 20 questions, obtaining as main findings that Facebook is the most used social network followed by Twitter and Instagram.

Keywords: political marketing; electoral marketing; political advertising; information and communication technology.

\section{Resumo}

Campanhas eleitorais realizadas pelos diferentes partidos políticos no âmbito das eleições processos democráticos são realizadas hoje oferecem a oportunidade, eles podem usar as tecnologias de informação e comunicação e, portanto, para divulgar e anunciar eleitoralmente seus candidatos e suas políticas e ideologias que forma, os eleitores podem escolher o melhor candidato, mas primeiro ser claro sobre os detalhes de sua escolha; É aqui que as tecnologias de informação e comunicação terão um papel importante na transmissão de mensagens publicitárias. Esta pesquisa tem por objetivo estudar a propaganda política com base na tecnologia de informação e comunicação, para a qual foi utilizada uma abordagem qualitativa e quantitativa, apoiada por uma pesquisa bibliográfica sobre as variáveis em estudo, além de uma investigação de campo foi realizado onde a população do estudo foi estruturada pelos habitantes da província de Tungurahua em idade de 16 a 65 anos que foram administrados a pesquisa como uma ferramenta para a recolha de informação em si que foi estruturado com 20 questões recebendo principais conclusões que o Facebook é a rede social mais utilizada, seguida pelo Twitter e pelo Instagram

Palavras chave: marketing político; marketing eleitoral; propaganda política; tecnologia da informação e comunicação.

\section{Introducción}

Las campañas electorales por parte de los diferentes partidos políticos dentro de los procesos democráticos de elecciones, son la oportunidad para utilizar las tecnologías de la información y comunicación y de esa manera publicitar electoralmente a sus candidatos a las distintas dignidades que se elegirán; así también analizar las estrategias electorales de los partidos así 
como de otros factores que son importantes y que direccionan las herramientas publicitarias aplicadas a la política (Agustín Valdés, 2014).

La importancia que tendrán las TIC, en la transmisión de mensajes durante esta campaña electoral se verá en la capacidad de construcción de los mismos como lo afirman (FernándezQuijada \& Otros, 2015, pág. 21) otro aspecto importante es la comunicación que juega un papel relevante, también es conveniente hablar del ciclo de vida de las tecnologías que tiene las siguientes fases: Investigación y desarrollo (I+D), Producción Industrial, Prescripción de usos, Adquisición y usos, Extensión de usos. Las TIC tienen un papel muy protagónico en todos los ámbitos de la vida y en lo que a la política respecta las cosas no se quedan al margen, tanto el impacto como el uso de estos medios digitales y la implementación de estrategias de marketing electoral (Postigo, 2012, pág. 177).

Otro factor importante es la creación de una marca personal sobre la cual se relacionarán tanto el slogan como el proyecto político; mismo que se debe fortalecer empoderando social o populistamente a los candidatos y de esa manera posicionándose en todos los espacios digitales disponibles. (Rivera Costales, 2014, pág. 122)

De lo expuesto se considera como pregunta de investigación ¿Cuál es la influencia del tic en el marketing político?, cuya respuesta es a través del objetivo analizar los efectos de publicidad electoral basada en tecnologías de la información y comunicación (TIC)

\section{Marketing político}

Para (Juárez, 2003, pág. 63) citando a Lock y Harris (1996) definen marketing político como una disciplina orientada al "estudio de los procesos de los intercambios entre las entidades políticas, su entorno, y entre ellas mismas, con particular referencia al posicionamiento de estas entidades y sus comunicaciones" (p.21); en tanto que para (Saiz, 2003) el marketing político o marketing electoral se puede definir como un conjunto de tácticas y técnicas para conocer deseos y necesidades del mercado electoral, y establecer un programa ideológico que satisfaga ofreciendo a un candidato que personaliza ese programa apoyando e impulsándose en la publicidad política,

Por todo lo anterior es fundamental analizar primeramente el proceso de comunicación, mismo que consta de varias etapas entre ellas se puede mencionar según (Stanton, Etzel, \& Walker, 
2007, pág. 511) son: Diseño del mensaje, Codificación del mensaje, Transmisión del mensaje, Decodificación del mensaje, Recepción del mensaje, Respuesta, Retroalimentación y Ruido.

Utilizando el criterio de (Stanton, Etzel, \& Walker, 2007, pág. 511) en marketing político y el uso de TIC, cada etapa queda estructurada de la siguiente manera:

- Diseño del mensaje, por parte del emisor que en este caso será el partido político, mismo que se relacionará con la idea promocional que se pretende introducir en la mente del votante;

- Codificación del mensaje, en este caso serán todas aquellas aplicaciones relacionadas con el uso de TIC;

- Transmisión del mensaje es decir se Selecciona el canal del mensaje, es decir el medio o vehículo para transmitir el mensaje;

- Decodificación del mensaje, esto es que el receptor compara el mensaje con un marco de referencia;

- Mensaje recibido por los votantes quienes deberán cambiar su conocimiento, creencias o sentimientos con respecto al emisor del mensaje;

- Respuesta, misma que puede abarcar desde el simple reconocimiento hasta la aceptación de la idea política; es importante que se mida el impacto y se puede utilizar la investigación para determinar si los votantes aceptan la idea política y tienen una marcada intención de voto.

- Retroalimentación, que siempre servirá para replantear el diseño del mensaje volviendo así a la primera etapa haciendo de este un proceso que iniciará cuantas veces se desee;

Las etapas descritas deberán estar muy bien definidas, estructuradas y ser en sí muy claras a fin de eliminar el ruido del proceso de comunicación, el ruido son todos aquellos anuncios antagónicos (mensajes de los otros candidatos) y otras distracciones propias o ajenas que no dejan que el mensaje sea comprendido o entendido en su totalidad (Stanton, Etzel, \& Walker, 2007, pág. 511).

Es de suma importancia desarrollar una comunicación efectiva con los electores para esto se debe identificar claramente el público objetivo ya que esto influenciará la decisión del partido político 
en el qué, cómo, cuándo, dónde y a quién; se deben definir los objetivos de comunicación esto sirve para dirigirse a la mente del público y de esta manera decidir el cambio de actitud que se quiere conseguir, que será el de conseguir el voto, para esto se busca actuar sobre el nivel cognoscitivo, afectivo o de comportamiento del público electoral; en lo referente al diseño del mensaje es vital desarrollar un mensaje efectivo que consiga la atención, el interés y provoque deseo y acción; de acuerdo con (Filzmaier \& Moreno, 2013, pág. 37) la comunicación política es cualquier forma de transmisión política que abarca información, participación, comunicación y campaña política. Para que esto sea posible se debe tomar en cuenta el contenido del mensaje, la estructura, formato y la fuente del mismo; la selección de canales eficientes garantizará que el mensaje llegue al electorado; un aspecto que se debe tomar en cuenta es el presupuesto de comunicación y de medios; finalmente se tiene que decidir al respecto de cómo distribuir el presupuesto total de comunicación.

Las principales decisiones que se toman en una campaña promocional son al respecto de: tener establecidos los objetivos, decidir lo referente al presupuesto, tomar la decisión del mensaje, así también escoger los medios y finalmente evaluar los resultados; éstas cinco decisiones son cruciales al momento de comunicar o promocionar algo o a alguien, de la misma manera son importantes al tratarse de una campaña electoral que ocupa TIC como su medio principal de comunicación; para (Fara, Fernández, Guberman, Reina, \& Reina, 2013) el tomar la decisión de una campaña política 2.0 implica contar con una estrategia integral que permita alcanzar los objetivos propuestos y el posicionamiento del proyecto político.

El establecimiento de objetivos en una campaña ayuda a conocer al público objetivo sus características socio-económicas, demográficas y psicográficas; con esto se puede provocar el comportamiento deseado (votos para el partido y candidato), esto sería el objetivo fundamental; para (Túñez-López, García, \& Guevara-Castillo, 2011, pág. 56) se debe establecer un marketing de relaciones que supone la orientación a largo plazo beneficiando a todas las partes implicadas; sin descuidar los fines con los cuales se establecen los objetivos en la campaña que son el informar, persuadir y recordar; así también algo que no se debe dejar de lado es el proceso que un elector sigue antes de decidir dar su voto el proceso puede darse de la siguiente forma: iniciando con la notoriedad, seguido del conocimiento, apreciación, preferencia, convicción y finalmente acción. 
La decisión del presupuesto de campaña depende de los costos de producción que abarca todo el desarrollo de concepto, idea e imagen a promocionar; inserción o emisión que tienen que ver con lo costos de pautar en los diferentes espacios relacionados a las TIC; investigación esto se relaciona con el hecho de que debemos evaluar y verificar los resultados de la campaña y determinar si el mensaje, idea e imagen llegan de la manera pensada y se están logrando todos los propósitos establecidos con anterioridad. En cuanto a la manera de determinación del presupuesto de la campaña el Ecuador en sus leyes establece los límites de gasto electoral. (Gobierno Ecuatoriano, 2016)

En lo referente al mensaje publicitario de la campaña, éste debe tener un contenido acorde al posicionamiento del candidato en la mente del electorado; la forma del mensaje debe dejar en claro la imagen y slogan del partido; para la creación se lo debe realizar con una agencia publicitaria, que se encargue del desarrollo creativo y adaptación a las TIC.

Los medios de comunicación serán todos los relacionados a las TIC, por ende, serán medios audiovisuales en su mayoría, mismos que necesitan de una adecuada planificación que deberá tomar en cuenta: al público objetivo, el impacto, alcance, frecuencia y en razón de CPM (costos por mil), medidos en OTS (Opportunity to see) y OTH (Opportunity to hear).

Es conveniente analizar también el proceso electoral, primeramente, indicando que cargos son los que se elegirán el 19 de febrero de 2017, las autoridades a elegirse son: Presidente y Vicepresidente de la república, parlamentarios andinos, asambleístas nacionales y provinciales y asambleístas por el exterior. En lo referente a los requisitos estos cambian conforme a la dignidad que se elige; en todas las mayorías de edad y estar en goce de los derechos políticos y no tener ninguna de las prohibiciones que se establecen el Código de la Democracia, para presidente se tiene que tener 30 años y ser ecuatoriano de nacimiento y para asambleístas provinciales tienen que haber nacido o residido por lo menos dos años ininterrumpidos en la localidad por la cual postula. En cuanto al proceso de registro de candidaturas éste inicia al interior de las organizaciones políticas, ya que es allí donde y por medio de procesos democráticos y alianzas se establecen quiénes serán los candidatos para las distintas dignidades (Ycaza Vinueza, 2016, págs. 8-9). Posterior a esto el partido político tendrá que llenar los formularios para inscripción de los candidatos, el formulario se lo entrega a las secretarías del Consejo Nacional Electoral y Juntas 
Provinciales información que se entrega digitalizada; esta información se hace pública para que el resto de organizaciones políticas puedan impugnar de ser necesario alguna de las candidaturas y de no haber impugnaciones la Dirección de Organizaciones Políticas verifica que se cumplan todos los requisitos de ley; entre estos el plan de trabajo de acuerdo a la dignidad a la que se postule, para que se dé a conocer lo que proponen a la colectividad.

Las tecnologías de información y comunicación se utilizan para difundir además de los planes de gobierno principalmente la imagen o marca personal del candidato para (Hughes, 2007, pág. 1114) esto es una novedad en marketing, que hay que seguir investigando; además de que examina la relación entre la marca personal y el marketing político, realizando una comparación entre la teoría de aprobación de las celebridades y la marca personal y así sustentar la propuesta de que la marca personal es la más apropiada para usarla en marketing político; como se puede ver es determinante trabajar en la imagen y marca personal de los candidatos y más aún asociarla a un slogan de la campaña, previa a una elección se habla de marketing electoral igual qué, o en lugar de, marketing político.

\section{Materiales y métodos}

La presente investigación cuenta con un enfoque cuali-cuantitativo, que lo describe Hernández, Fernández y Baptista (2014) "El enfoque cuantitativo utiliza la recolección de datos para probar hipótesis con base a la medición numérica y el análisis estadístico, con el objetivo de establecer pautas de comportamiento y probar teorías" (p. 4).

Es decir, se trabaja con datos estadísticos los cuales permiten identificar el fenómeno problemático además de tabular los datos recabados a través de la encuesta realizada.

Por otro lado, Hernández et al. (2014) Indican que "La investigación cualitativa se enfoca en comprender los fenómenos, explorándolos desde la perspectiva de los participantes en un ambiente natural y en relación con su contexto" (p. 358).

Es cualitativo porque va de lo general a lo particular, explorando y describiendo las causas que generan la aparición del problema para luego proporcionar perspectivas teóricas, enfocándose en la lógica y luego en los procesos inductivos, además a través de la observación se obtiene importante información para la construcción de la investigación. 
Dentro de la presente investigación se desarrolló la investigación bibliográfica que según Diaz, Castro, León y Ramírez (2015) definen la investigación bibliográfica como "se trata de textos impresos o escritos que aportan una visión de conjunto de un tema específico y que suelen estar publicadas en forma de libro o compilación encuadernada, cosida o cubierta con una pasta” (p. 24).

Es por ello que, con esta modalidad de investigación se pudo obtener información de publicidad política, tecnologías de información y comunicación con base a libros, documentos electrónicos, revistas científicas, etc., que sirvieron para la estructuración del estado del arte.

Por otro lado, también se utilizó la investigación de campo misma que según Miller (2011) es definida como "se apoya en información del objeto de estudio o de los involucrados en él, a partir de indagación de campo como en la investigación" (p. 3).

Bajo esta perspectiva se desarrolló esta modalidad de investigación pues permitió conocer a ciencia cierta la realidad de la población objeto de estudio en torno a la publicidad política y las tecnologías de información y comunicación, además se obtuvo un contacto directo con la población en donde se recolecto información primaria a través de la encuesta aplicada.

El objetivo de la presente investigación es conocer las situaciones y actitudes de los involucrados a través de la descripción de actividades utilizando como principal método para recoger información una encuesta estructurada e inclusive la observación misma, aplicándose un enfoque descriptivo de investigación por tratarse de un estudio exploratorio en base a un trabajo de campo (Gómez, 2006, págs. 70-71).

Según Sabado (2011) la población es "el conjunto de todos los individuos que cumplen con ciertas propiedades, características y de quienes se desea estudiar ciertos datos” (p. 21). Para la presente investigación se tomó como referencia a la población de Tungurahua en edades comprendidas entre 16 a 65 años de edad, es decir 319.297 habitantes se trabaja con esta población y en la provincia de Tungurahua por considerarla como una provincia importante, ya que en esta convergen muchos aspectos como son económicos, políticos, sociales, esto por encontrarse ubicada en el centro del país. 
Para Ludwing (2014) la muestra puede ser definido como "un subconjunto de la población, que se obtiene para averiguar las propiedades o características de esta última, por lo que interesa que sea un reflejo de la población, que sea representativa de ella" (p. 2). Una vez aplicado la formula respectiva se obtuvo como muestra un total de 360 individuos a quienes se les aplico una encuesta estructurada a fin de conocer aspectos relacionados con la publicidad política y las tecnologías de información y comunicación.

Se utiliza una encuesta, con 20 preguntas de tipo cualitativo, de lo cual se aplica prueba piloto, cuyos resultados son validados a través de coeficiente de incertidumbre con valor-p 0.12; lo cual indica que los resultados son estables, haciendo válido el instrumento para recolección de información.

El instrumento fue aplicado a una muestra de 360 habitantes de entre 16 y 65 años de edad, de la provincia de Tungurahua, esto fue una encuesta estructurada por 20 preguntas y fin de conocer aspectos relacionados con la publicidad política y las tecnologías de información y comunicación; la misma que ha sido aplicada.

\section{Resultados}

Los resultados se han procesado a partir de la información recopilada y procesada con el programa SPSS, y expresada a través de estadística descriptiva e inferencial.

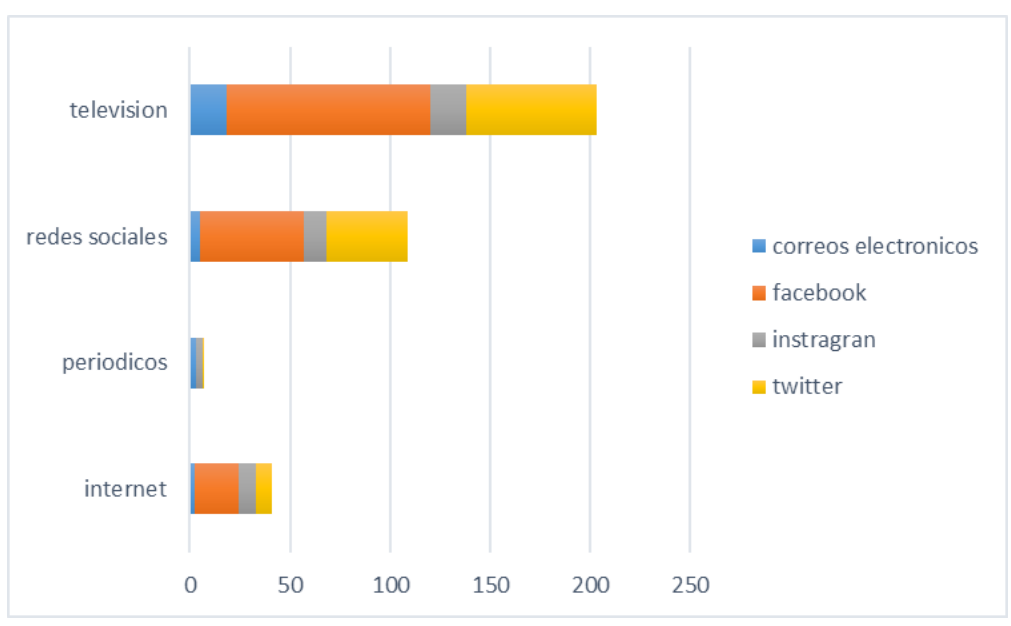

Figura 1. Relación entre la comunicación y redes sociales Elaborado por: autores 
En lo referente a que si la tecnología, en la Figura 1, el 53\% de personas asegura que la tecnología no ayudará en esta campaña electoral. Así también, la manera en que se enteran las personas de las noticias relacionadas con los partidos políticos de su preferencia, de las personas encuestadas, el $56 \%$ asegura que se entera de noticias relacionadas con su partido político a través de la TV, el $30 \%$ asegura que se entera de noticias relacionadas con su partido político a través de las redes sociales. La frecuencia con que se utilizan las redes sociales el $49 \%$ utilizan con frecuencia la red social de Facebook, el 32\% Twitter. Donde se nota mayor presencia de Twitter en quienes miran televisión y utilizan redes sociales.

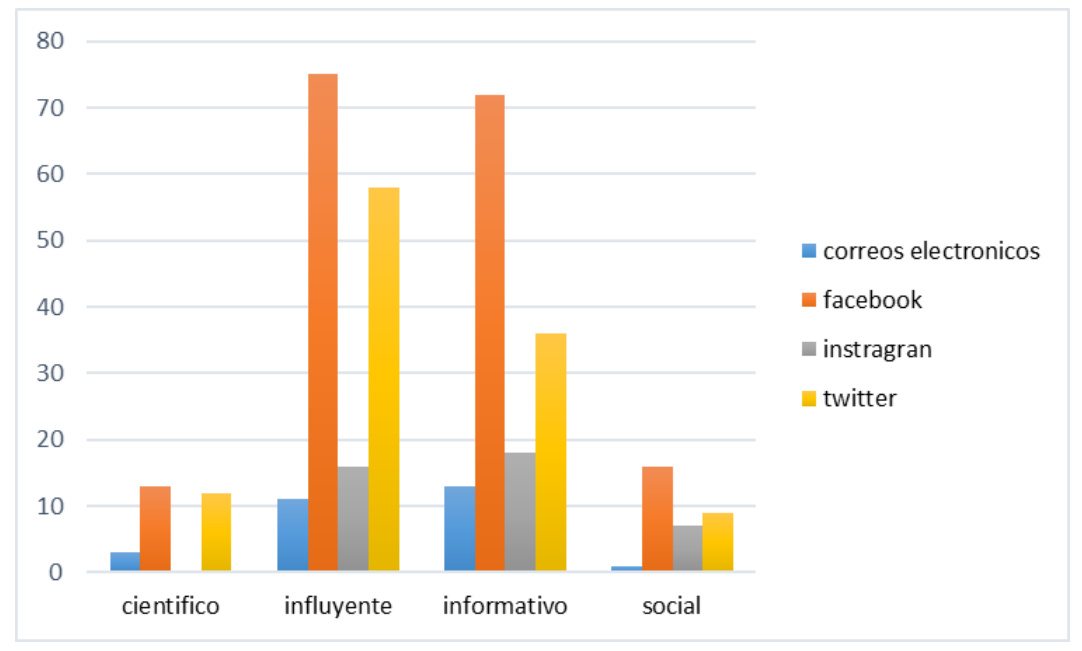

Figura 2. Relación entre el tipo de mensaje y redes sociales

\section{Elaborado por: autores}

El carácter de los mensajes que se reciben de los partidos políticos por medio de redes sociales, es influyente por redes sociales, de lo cual se destaca Facebook y Twitter; donde el $44 \%$ de personas asegura que el mensaje que recibe de los partidos políticos por medio de redes sociales es influyente, el $39 \%$ que es informativo. 


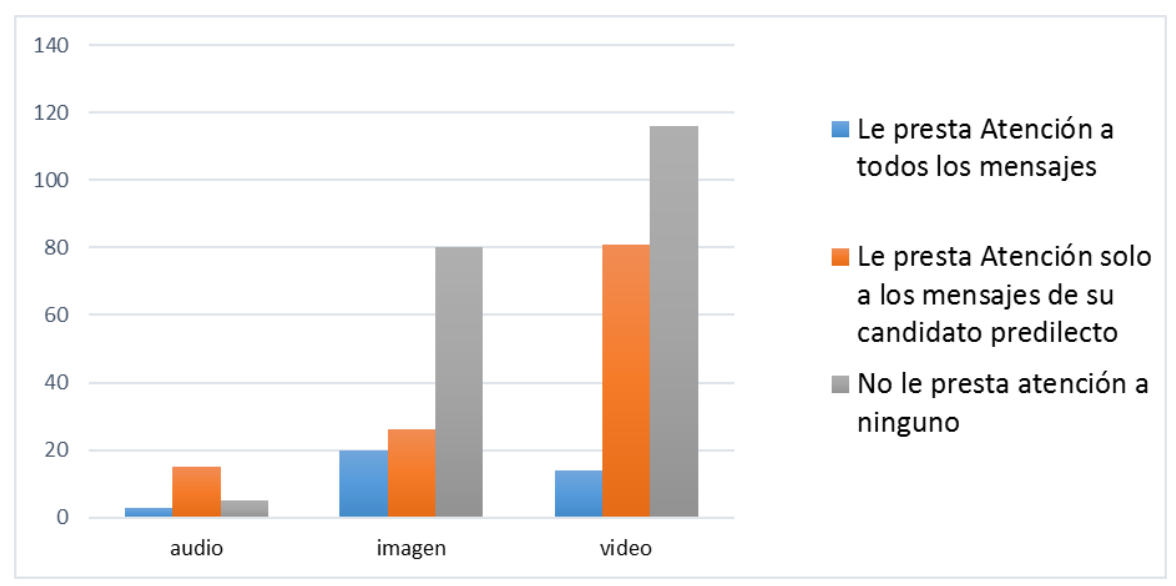

Figura 3. El tipo de mensaje en relación a la reacción

\section{Elaborado por: autores}

El 53\% de las personas encuestadas asegura que, si es fácil obtener información política por medios tecnológicos; siendo el principal medio la transmisión de videos a través de redes sociales, siendo que el $56 \%$ asegura no tener reacción frente a los mensajes recibidos.

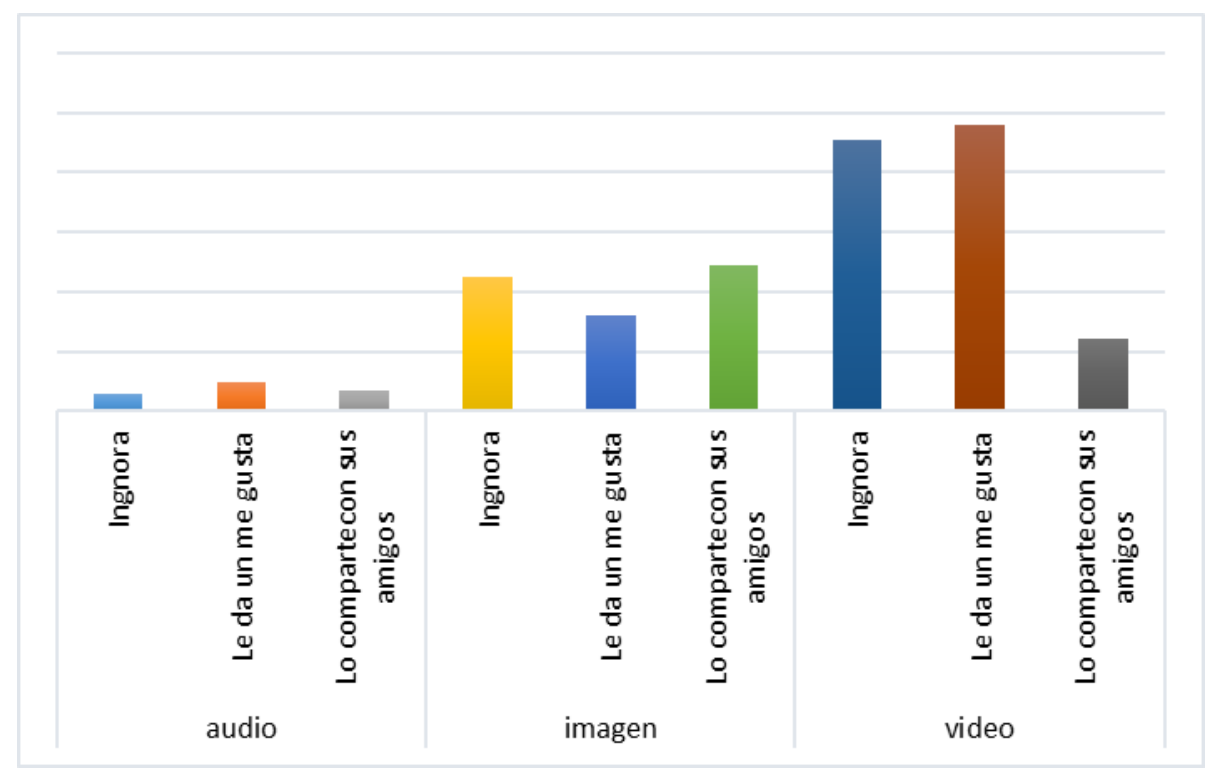

Figura 4. Acciones frente a los mensajes

Elaborado por: autores

La publicidad que llega por redes sociales es considera como un material adecuado para ser compartido en cuanto a imágenes, pero los videos son ignorados o colocados con "me gusta" como símbolo de apoyo. 


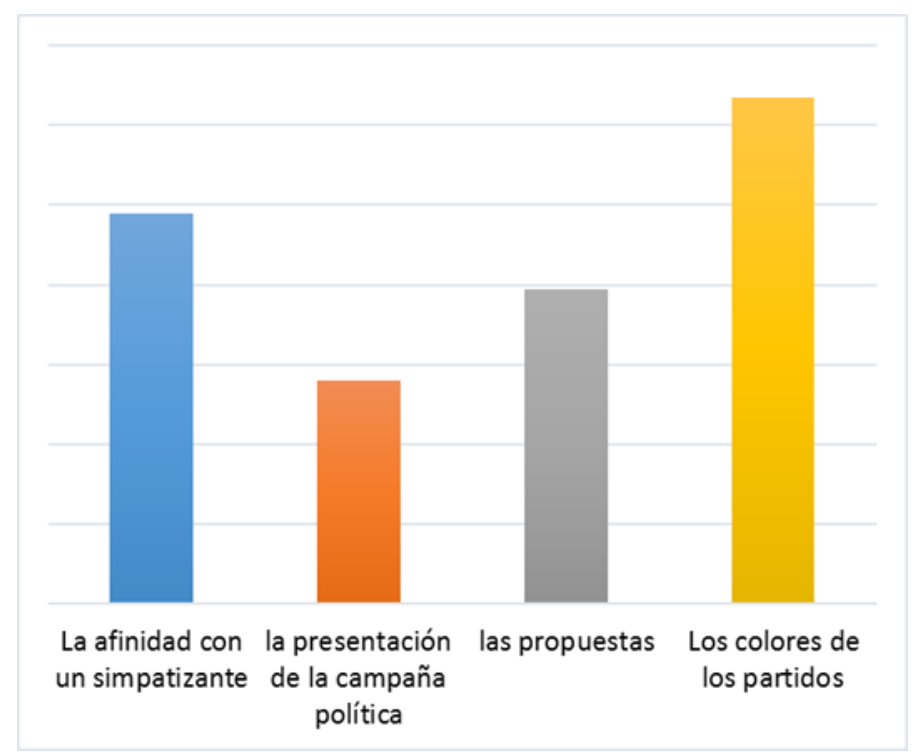

Figura 5. Características de los anuncios

Elaborado por: autores

Las características que llaman la atención en un anuncio publicitario de un partido político, el $35 \%$ son los colores, el $27 \%$ la afinidad con un simpatizante, el $22 \%$ son las propuestas. Siendo necesario la difusión de estos elementos mediante redes sociales y medios de comunicación.

En la Tabla 1, se muestra la relación entre el medio utilizado para recibir las noticias de la campaña electoral, la reacción frente al mensaje y la valoración de la campaña electoral. Es decir, que hay evidencia que las tecnologías de la comunicación e información influyen sobre las percepciones de los votantes durante la campaña electoral.

\begin{tabular}{|c|c|c|}
\hline & Noticias & $p$-value \\
\hline Reacción &, $111^{*}$ & ,035 \\
\hline Características & $149^{* *}$ & 0.005 \\
\hline
\end{tabular}

\section{Conclusiones}

Las nuevas tecnologías de la información y comunicación permiten establecer nuevas actividades de participación política que anteriormente no existían con base a espacios virtuales donde se 
propicie una interacción político-social con el objetivo de consumir información política, además de realizar intercambios de ideas, estas características permiten que el internet sea considerado por su poder democratizador en una herramienta de acceso e interacción igualitaria entre los individuos sobre temas de cualquier índole.

Se puede determinar también que las nuevas tecnologías que han aparecido no han cambiado el carácter de la participación política, únicamente son nuevos medios para que los políticos y sus diferentes partidos difundan su mensaje político y lleguen a una mayor cantidad de personas.

De acuerdo a la investigación de campo desarrollada se puede establecer que, en Tungurahua, el movimiento con mayor cantidad de adeptos es Alianza País (24\%), seguido muy de cerca por el Movimiento CREO (19\%), estas dos agrupaciones realizan una muy buena publicidad política con base a las nuevas tecnologías de información y comunicación enfocándose en cada uno de los colores de cada agrupación y la afinidad con cada uno de los simpatizantes.

Facebook representa la red social de mayor preferencia entre los encuestados y es en esta plataforma virtual donde reciben publicidad electoral ya sea en imágenes, videos o audios.

\section{Referencias bibliográficas}

Agustín Valdés, J. d. (2014). Propaganda política y publicidad comercial: Análisis comparativo. Barcelona: Universidad Autónoma de Barcelona.

Díaz, M., Castro, D., León, A., \& Ramírez, M. (2015). Metodología de la investigación. México D.F., México.

Fara, C., Fernández, J., Guberman, L., Reina, A., \& Reina, M. (2013). Campañas electorales e Internet. En C. Fara, J. Fernández, L. Guberman, A. Reina, \& M. Reina, Acciones para una buena comunicación en campañas electorales: manual de marketing y comunicación política (pág. 259). Buenos Aires: Konrad Adenauer Stiftung.

Fernández-Quijada, D., \& Otros, \&. (2015). Tecnologías de la persuasión uso de las TIC en Publicidad y Relaciones Públicas. Barcelona: UOC (Oberta UOC Publishing, SL).

Filzmaier, P., \& Moreno, G. (2013). Campañas con Estrategia: Fundamentos y herramientas para una comunicación política efectiva. Más Poder Local Investigación, 36-45. 
Gobierno Ecuatoriano. (17 de Noviembre de 2016). http://www.inae.gob.ec. Obtenido de http://www.inae.gob.ec: http://www.inae.gob.ec/wp-content/uploads/Registro-Oficial-449.pdf

Gómez, M. (2006). Introducción a la metodología de la investigación científica. Córdoba: Brujas.

Hernández Sampieri, R., Fernández Collado, C., \& Baptista Lucio, P. (2014). Metodología de la investigación. México D.F.: McGrawHill.

Hughes, A. (2007). Personal Brands: An Exploratory Analysis of Personal Brands in Australian Political Marketing. In Australia and New Zealand Marketing Academy Conference (págs. 11141120). Dunedin: University of Otago.

Juárez, J. (2003). Hacia un estudio del marketing político: limitaciones teóricas y metodológicas. Espiral, Estudios sobre Estado y Sociedad, 61-95.

Ludewig, C. (2014). Universo y muestra. México D.F., México.

Miler Daen, S. T. (2011). Tipos de investigación científica. Santa Cruz, Bolivia.

Postigo, M. A. (2012). Campaña en la red: estrategias de marketing electoral en Internet. Redmarka: revista académica de marketing aplicado, 177.

Rivera Costales, J. R. (2014). Rafael Correa y las elecciones 2006. Chasqui, 118-123.

Sabado, J. (2011). Fundamentos de bioestadística y análisis de datos. Barcelona, España.

Saiz, F. J. (2003). Marketing político. Rioja: Escuela Superior de Gestión Comercial y Marketing, ESIC.

Stanton, W. J., Etzel, M. J., \& Walker, B. J. (2007). Fundamentos de Marketing. México, D. F.: McGraw-Hill Interamericana Editores, S. A.

Túñez-López, M., García, J. S., \& Guevara-Castillo, M. (2011). Redes sociales y marketing viral: repercusión e incidencia en la construcción de la agenda medíatica. Palabra Clave, 53-65.

Ycaza Vinueza, F. (2016). Proceso de inscripción de Candidaturas. Opinión Electoral Gaceta de Análisis Electoral, 8-9. 